\title{
Dietary $n-3$ PUFA content as a modulator of the femur properties in growing pigs
}

\author{
Monika Sobol*, Grzegorz Skiba and Stanisława Raj \\ Department of Animal Nutrition, The Kielanowski Institute of Animal Physiology and Nutrition, Polish Academy of Sciences, \\ Instytucka 3 Street, 05-110 Jabłonna, Poland
}

(Submitted 9 March 2018 - Final revision received 26 November 2018 - Accepted 27 November 2018 - First published online 29 January 2019)

\section{Abstract}

The relationships between both dietary and empty body fatty acid composition and the morphometry, densitometry, geometry and biomechanical properties of the femur of growing pigs were analysed. A total of thirty-two pigs aged $115 \mathrm{~d}$ were divided into four groups ( $n 8$ per group). The pigs were fed either a control diet (group C) or a diet supplemented with linseed oil (rich in $\alpha$-linolenic acid (C18:3n-3), group L), fish oil (rich in EPA (C20:5n-3) and DHA (C22:6n-3), group F) and beef tallow (rich in SFA, group T). The diets differed in $n$-3 PUFA contents $(0.63-18.52 \mathrm{~g} / \mathrm{kg})$ and $n-6: n-3$ PUFA ratios (0.91-14.51). At $165 \mathrm{~d}$ of age, the pigs were slaughtered and the fatty acids in the empty body were determined. Moreover, the left femur was dissected. The cortical wall thickness, cross-sectional area, cortical index, bone mineral content, bone mineral density, maximum elastic strength and maximum strength were lower $(P<0.05)$ in the femurs of pigs from groups $\mathrm{C}$ and $\mathrm{T}$ than in those from groups $\mathrm{F}$ and $\mathrm{L}$. Significant positive correlations were found between the densitometry, geometry and biomechanical properties of the femur and both dietary and empty body $n-3$ PUFA content, whereas significant negative correlations were observed between the same properties and both dietary and empty body $n-6: n-3$ PUFA ratio. The results of the present study suggest that in growing pigs $\alpha$-linolenic acid has a similar positive effect on bone health to that of EPA and DHA.

Key words: Bone mineralisation: Fatty acids: Femur: Pigs: X-ray absorptiometry

Nutrition has the greatest effect on bone growth, as it influences the accumulation of minerals and therefore affects the intensity of bone formation and resorption processes in bone turnover. Dietary intake of energy, protein and mineral components (e.g. $\mathrm{Ca}, \mathrm{P}$ ) is known to be critical for attaining and maintaining a healthy skeletal reserve ${ }^{(1-4)}$. It has been known for decades that a diet rich in SFA can adversely affect bone mineralisation in growing rats ${ }^{(5)}$ and quails ${ }^{(6)}$. Recently, PUFA, particularly EPA (C20:5n-3), docosapentaenoic (DPA, C22:5n-3) and DHA (C22: 6n-3), have drawn interest as natural substances that can affect bone metabolism at the cellular level ${ }^{(7,8)}$. Supplementation of the diet with EPA and DHA (from fish oil) improved bone health in rodents ${ }^{(9-14)}$, quails ${ }^{(6,15)}$ and piglets ${ }^{(16,17)}$. Parks ${ }^{(8)}$ suggested that both long-chain $n$ - 3 and $n-6$ PUFA have beneficial effects on bone modelling in children. However, the results of a study carried out by Judex et al. ${ }^{(18)}$ demonstrated that dietary EPA and DHA (from fish oil) supplementation adversely affects cortical bone morphology and biomechanics in growing rabbits.

In North America and Europe, the majority of dietary intake of $n-3$ PUFA is derived from rapeseed and linseed oils (rich in $\alpha$-linolenic acid (ALA, C18:3n-3)). A review of the available literature identified only a few studies that have investigated the effect of feeding animals a diet rich in ALA on bone health. However, these studies were carried out mainly on rodents $^{(11,19)}$ and poultry ${ }^{(20)}$ and the results were inconclusive. The studies were limited mainly to bone mineral density and maximum bone strength, whereas the health properties of bone are represented by a greater number of parameters (including geometry, densitometry and biomechanical indicators).

A review of the current literature ${ }^{(21,22)}$ revealed that there are differences between the type and quantity of dietary $n$-3 PUFA on bone quality and structure. However, there was no simultaneous comparison of the effect of diets rich in ALA $v$. those rich in EPA and DHA on bone properties. Moreover, dietary $n-6: n-3$ PUFA ratio seems to have a great impact on bone parameters; however, this issue has only been studied in quails $^{(6)}$ and rodents ${ }^{(10,18)}$. We consider that all mentioned above issues are essential for the prevention of common bone diseases in humans, such as osteopenia and osteoporosis. Therefore, the present study had two aims. Our first aim was to determine the effect of the dietary source of fats (differing in $n$-3

Abbreviations: AA, arachidonic acid; ALA, $\alpha$-linolenic acid; C, group of pigs fed a control diet; F, group of pigs fed a diet rich in EPA and DHA (from fish oil); L, group of pigs fed a diet rich in $\alpha$-linolenic acid (from linseed oil); LA, linoleic acid; T, group of pigs fed a diet rich in SFA (from beef tallow).

* Corresponding author: Dr M. Sobol, email m.sobol@ifzz.pl 
PUFA content and n-6:n-3 PUFA ratio) on morphometry, densitometry, geometry and biomechanical parameters of the femur in growing pigs. Our second aim was to define the relationships between both dietary and empty body $n-3$ PUFA content and $n-6: n-3$ PUFA ratio and bone properties.

\section{Methods}

The experimental procedures used throughout this study were performed in accordance with national/local ethical guidelines and were approved by the III Local Ethics Committee on Animal Experimentation at the Warsaw University of Life Sciences SGGW, Poland.

\section{Animals, housing and diets}

The experiment was carried out on thirty-two gilts (Polish Large White $\times$ Danish Landrace). At $115 \mathrm{~d}$ of age (approximately $60 \mathrm{~kg}$ body weight), the pigs were divided into four groups ( $n 8$ per group) and were fed either a control diet (not supplemented with any source of fat, group C) or a diet supplemented with linseed oil (rich in ALA, group L), fish oil (rich in EPA and DHA, group F) and beef tallow (rich in SFA, group T) for the next $50 \mathrm{~d}$ (until the pigs were $165 \mathrm{~d}$ of age, approximately $105 \mathrm{~kg}$ body weight). In experimental diets the amount of energy added as fat accounted for $10 \%$ of metabolisable energy. Diets were isoenergetic (average $13.55 \mathrm{MJ}$ metabolisable energy $/ \mathrm{kg}$ ) and isolysinic (average $8.20 \mathrm{~g}$ of standardised ileal digestible lysine $/ \mathrm{kg}$ ) but differed in their $n$ - 3 PUFA contents $(0.63-18.52 \mathrm{~g} / \mathrm{kg})$ and $n$ 6:n-3 PUFA ratios (0.91-14.51). The content of metabolisable energy, standardised ileal digestible amino acids and total $\mathrm{P}$ in the diets were calculated as detailed by nutrient requirements of swine ${ }^{(23)}$. Diets were supplemented with a mineral-vitamin mixture and crystalline amino acids, according to nutrient requirements of swine guidelines ${ }^{(23)}$. The composition, nutritive value and energy contents of each of the diets are presented in Table 1 . The dietary fatty acid contents are presented in Table 2.

The animals were kept individually in pens $\left(3.3 \mathrm{~m}^{2}\right)$ equipped with nipple drinkers, on a concrete floor without straw. Pigs had olfactory, auditory, visual and physical contact with each other. Dry, granulated feed was offered at a dose of $85 \%$ ad libitum twice daily (at 08.00 and 14.30 hours). Restricted feeding allowed the full control of fatty acid intake. The environmental conditions in the piggery were as follows: air temperature $\left(18-20^{\circ} \mathrm{C}\right)$, relative humidity $(60-70 \%)$ and air flow $(0 \cdot 2-0.4 \mathrm{~m} / \mathrm{s})$ regulated by a Fancom ventilation system (model ISM0.12; Fancom BV) and in accordance with the European Union law ${ }^{(24)}$.

\section{Sample collection, measurements and calculations}

At $165 \mathrm{~d}$ of age, the pigs were slaughtered. Before slaughter, pigs were electrically stunned (STZ 3 apparatus; P.P.H. MASTER Sp. J.), exsanguinated and scalded to remove hair. Blood was collected and weighed, the abdominal cavity was opened and the internal organs and the gastrointestinal tract were removed, emptied and weighed. The carcasses were weighed and then chilled at $4^{\circ} \mathrm{C}$ for $24 \mathrm{~h}$, after which each right half-carcass was dissected into edible (meat and fat) and inedible (bone, skin) parts. Blood, internal organs and the gastrointestinal tract (offal) were autoclaved $\left(130^{\circ} \mathrm{C}, 1.25\right.$ atmosphere pressure) for $8 \mathrm{~h}$, as were all inedible parts. Following, a $500 \mathrm{~g}$ sample of each separated body parts was collected, homogenised and used for chemical analysis (protein, diethyl ether extract, ash) and fatty acid composition. Mass of edible and inedible parts was established in relation to the whole carcass. Empty body was calculated as the sum of edible, inedible and offal parts.

After exsanguination, the left femur was dissected. Following excision, the bones were cleaned of any remaining flesh, weighed and frozen $\left(-20^{\circ} \mathrm{C}\right)$ for subsequent dual-energy X-ray absorptiometry scanning with a Norland XR- $800^{\mathrm{TM}}$ densitometer scanner with a 'Research Scan' type (Norland, A Cooper Surgical Company). The dual-energy X-ray absorptiometry scans were obtained by standard procedure supplied by the manufacturer for scanning and analysis. A quality assurance test to verify the stability of the system calibration (control scans) was performed on a daily basis. A daily calibration procedure was performed using a QC Phantom and QA Calibration standard (Norland, A Cooper Surgical Company). Specimens for scanning were thawed at room temperature $\left(23^{\circ} \mathrm{C}\right)$ for $12 \mathrm{~h}$ before use. During scanning, the femur was positioned horizontally with the femoral head facing upwards, and the condyles downwards, and then scanned from the distal to the proximal end. All the scans were performed in triplicate to avoid any rotation of the bone, as inconsistencies in their orientation can adversely affect the accuracy of test results. To ensure consistency, all scans were performed by the same operator. Bone mineral content and bone mineral density were recorded. After dual-energy X-ray absorptiometry scanning, the three-point bending test using a TA-HDi Texture Analyser (Stable Micro Systems Ltd) was applied to determine the biomechanical properties of the femur. The distance between supports of the bone was set at $40 \%$ of the femur length and the measuring head loaded bone samples at the midshaft with a constant speed of $50 \mathrm{~mm} / \mathrm{min}$. The values of maximum bone strength and maximum bone elastic strength were determined. The geometrical properties of each femur were determined on the basis of the measurements of horizontal and vertical diameters (both external and internal) recorded after cutting the bone. The measurements were conducted using an electronic ruler.

The values of cortical wall thickness $(\mathrm{mm})$, cross-section area $\left(\mathrm{mm}^{2}\right)$ and cortical index (\%) were determined using the following mathematical formulas:

$$
\text { Cortical wall thickness }=\frac{((V+H)-(v+h))}{4}
$$

$$
\text { Cross-section area }=\frac{\pi \times((H \times V)-(b \times v))}{4}
$$

$$
\text { Cortical index }=\left(\left(\frac{H-b}{H}+\frac{V-v}{V}\right) \div 2\right) \times 100
$$

where $V$ is the vertical external diameter $(\mathrm{mm}), H$ is the horizontal external diameter $(\mathrm{mm}), v$ is the vertical internal diameter $(\mathrm{mm})$ and $b$ is the horizontal internal diameter $(\mathrm{mm})^{(25)}$. 
Table 1. Ingredients, chemical composition and nutritive value of diets

\begin{tabular}{|c|c|c|c|c|}
\hline Indices & Control diet & Linseed oil diet & Fish oil diet & Beef tallow diet \\
\hline \multicolumn{5}{|l|}{ Ingredients (g/kg) } \\
\hline Barley & 305 & 325 & 325 & 325 \\
\hline Wheat & 300 & 360 & 360 & 360 \\
\hline Maize & 250 & - & - & - \\
\hline Soyabean meal & 40 & 40 & 40 & 40 \\
\hline Rapeseed meal & 80 & 80 & 80 & 80 \\
\hline Wheat bran & - & 120 & 120 & 120 \\
\hline Linseed oil & - & 50 & - & - \\
\hline Fish oil & - & - & 50 & - \\
\hline Beef tallow & & & & 50 \\
\hline Premix ${ }^{*}$ & 25 & 25 & 25 & 25 \\
\hline \multicolumn{5}{|l|}{ Chemical composition $(\mathrm{g} / \mathrm{kg})$} \\
\hline DM & 891 & 903 & 890 & 900 \\
\hline Ash & 38 & 41 & 45 & 44 \\
\hline Organic matter & 851 & 862 & 845 & 856 \\
\hline Crude protein & 158 & 162 & 160 & 163 \\
\hline Diethyl ether extract & 24.8 & 67.4 & 68.0 & $62 \cdot 7$ \\
\hline Crude fibre & 34.0 & 40.2 & 43.2 & $42 \cdot 2$ \\
\hline $\mathrm{N}$-free extract & 634 & 592 & 564 & 588 \\
\hline Total P & 3.98 & 3.98 & 4.01 & 3.96 \\
\hline Total Ca & 4.58 & 4.58 & 4.61 & 4.55 \\
\hline $\mathrm{Na}$ & 1.03 & 1.03 & 1.05 & $1 \cdot 10$ \\
\hline \multicolumn{5}{|l|}{ Amino acid content } \\
\hline Lys† & $8 \cdot 17$ & 8.19 & 8.23 & $8 \cdot 19$ \\
\hline Met† & $2 \cdot 83$ & $2 \cdot 81$ & $2 \cdot 82$ & $2 \cdot 80$ \\
\hline Thrt & 5.59 & 5.49 & 5.50 & 5.55 \\
\hline Trp† & 1.46 & 1.45 & 1.42 & 1.47 \\
\hline Metabolisable energy $(\mathrm{MJ} / \mathrm{kg}) \dagger$ & 13.45 & 13.58 & $13 \cdot 60$ & 13.58 \\
\hline Lys/metabolisable energy (g/MJ) & 0.61 & 0.60 & 0.61 & 0.60 \\
\hline
\end{tabular}

* Addition of $2.5 \%$ premix ( $\mathrm{A}$ - in control diet, B - in experimental diets) introduce to $1 \mathrm{~kg}$ of diet: vitamin $\mathrm{A} 450 \mu \mathrm{g}$, vitamin $\mathrm{D}_{3}$ 7.5 mg; Fe $60 \mathrm{mg}$, Zn $50 \mathrm{mg}$, Cu $30 \mathrm{mg}$, Mn $30 \mathrm{mg}$, I $0.30 \mathrm{mg}$, Se $0.20 \mathrm{mg}$, vitamin E $40 \mathrm{mg}$ (premix A) or $150 \mathrm{mg}$ (premix B), vitamin $K_{3} 2.0 \mathrm{mg}$, vitamin $B_{1} 2.0 \mathrm{mg}$, vitamin $B_{2} 2.5 \mathrm{mg}$, vitamin $B_{6} 2.0 \mathrm{mg}$, vitamin $B_{12} 0.02 \mathrm{mg}$, biotin $0.11 \mathrm{mg}$, folic acid $0.6 \mathrm{mg}$, nicotinic acid $15 \mathrm{mg}$, calcium-D pantothenate $10 \mathrm{mg}$, choline chloride $500 \mathrm{mg}$; Ca $2.8 \mathrm{~g}, \mathrm{P} 0.07 \mathrm{~g}$ and essential amino acids: lysine $2.63 \mathrm{~g}$, methionine $0.68 \mathrm{~g}$, threonine $0.98 \mathrm{~g}$.

$\dagger$ Calculated according to nutrient requirements of swine ${ }^{(19)}$.

\section{Analysis of the diets}

DM, N, ash, crude fibre, diethyl ether extract and simple sugar contents in the diets were determined as detailed by Horwitz \& Latimer $^{(26)}$ (procedures: 934.01, 984.13, 942.05, 978.10, 920.39 and 974.06, respectively). Protein content was estimated as $\mathrm{N}(\mathrm{g} / \mathrm{kg}) \times 6 \cdot 25$. To determine the fatty acid composition of the diets, $1.5 \mathrm{ml}$ of potassium hydroxide was added to each dietary fat sample and the solution was heated at $75^{\circ} \mathrm{C}$ for $1 \mathrm{~h}$. Next, methyl esters were prepared by esterification with thionyl chloride ( $4 \%$ in methanol) and extraction with $n$-heptane. Fatty acid methyl esters were analysed using a GC-2010AF Shimadzu Gas Chromatograph (Shimadzu Europa GmbH) equipped with a flame ionisation detector. The derivatives were separated on a capillary column (BPX70, $60 \mathrm{~m}$ length, 0.25 mm internal diameter and $0.25 \mu \mathrm{m}$ film thickness). The operating conditions were as follows: carrier gas, helium; split ratio, 1:100; injector and detector temperature, $260^{\circ} \mathrm{C}$; the initial column temperature of $110^{\circ} \mathrm{C}$ was held for $5 \mathrm{~min}$, then increased to $200^{\circ} \mathrm{C}$ at a rate of $3.5^{\circ} \mathrm{C} / \mathrm{min}$ and was held for $2.5 \mathrm{~min}$, then increased to $205^{\circ} \mathrm{C}$ at a rate of $0.3^{\circ} \mathrm{C} / \mathrm{min}$, then increased to $215^{\circ} \mathrm{C}$ at a rate of $1.5^{\circ} \mathrm{C} /$ min and was held for 3 min. Individual fatty acid peaks were identified by comparison with the Supelco 37 Component FAME Mix (SUPELCO) commercial standard. The total fatty acid content was calculated separately for each diet as being $90 \%$ of the diethyl ether extract ${ }^{(27)}$.

\section{Analysis of the empty body}

The analysis of protein, diethyl ether extract and ash content in the empty body was calculated using the procedures described for the diets.

Lipids from samples of empty body were extracted with chloroform-methanol $(2: 1, \mathrm{v} / \mathrm{v})$, homogenised and filtered. Then, $800 \mathrm{ml}$ of filtrate was evaporated at $50^{\circ} \mathrm{C}$ (under $\mathrm{N}$ ) and analysed according to the procedure described for dietary fatty acid analysis.

\section{Statistical analysis}

Statistical analyses were performed using Statgraphics Centurion (version 16.1.18, 2011) software (StatPoint Technologies Inc.). With an $\alpha$ level of 0.05 , power established at $80 \%$ and an effect size of $0 \cdot 75$, the required total sample size was 32 (i.e. $n 8$ per group). The hypothesised effect size of 0.75 was calculated from the descriptive statistics of a previous study ${ }^{(6)}$. Post hoc calculations using the above-mentioned data indicated that the actual power achieved in this study was $83.1 \%$. Data are presented as means and standard deviations. The effect of diet on performance, fatty acids composition in the empty body and the femoral properties of pigs were analysed using a one-way ANOVA. When the $F$ ratio was significant, Tukey's honest significant difference post hoc analysis was performed. Statistical 
Table 2. Fatty acids content in the diets $(\mathrm{g} / \mathrm{kg})$

\begin{tabular}{|c|c|c|c|c|}
\hline Fatty acids & Control diet & Linseed oil diet & Fish oil diet & Beef oil diet \\
\hline SFA & $5 \cdot 20$ & $9 \cdot 12$ & $10 \cdot 82$ & $22 \cdot 51$ \\
\hline MUFA & 5.40 & $12 \cdot 50$ & 17.84 & $15 \cdot 73$ \\
\hline PUFA & $9 \cdot 77$ & $35 \cdot 34$ & 28.39 & $12 \cdot 88$ \\
\hline$n-6$ PUFA & $9 \cdot 14$ & $16 \cdot 82$ & 13.94 & $11 \cdot 15$ \\
\hline C18:2n-6 & 9.05 & $16 \cdot 80$ & 13.77 & 11.06 \\
\hline $\mathrm{C} 20: 4 n-6$ & 0.09 & 0.02 & 0.17 & 0.09 \\
\hline$n-3$ PUFA & 0.62 & 18.52 & 14.44 & 1.73 \\
\hline C18:3n-3 & 0.62 & 18.52 & $6 \cdot 23$ & 1.73 \\
\hline $\mathrm{C} 20: 3 n-6$ & ND & ND & ND & ND \\
\hline $\mathrm{C} 20: 5 n-3$ & ND & ND & $3 \cdot 17$ & ND \\
\hline $\mathrm{C} 22: 5 n-3$ & ND & ND & 0.45 & ND \\
\hline C22: $6 n-3$ & ND & ND & 4.59 & ND \\
\hline$n-6: n-3$ PUFA & 14.74 & 0.91 & 0.96 & $6 \cdot 42$ \\
\hline
\end{tabular}

ND, value below 0.01 was classified as not determined.

significance was set at $P<0 \cdot 05$. A borderline significant trend was set at $P<0.09$.

The relationships between both dietary and empty body $n-3$ PUFA content and n-6:n-3 PUFA ratio and the geometric, biomechanic and densitometric properties of the femur were expressed as a linear regression model according to the following formula:

$Y=a+\beta X$

where $Y$ is the geometric or biomechanic or densitometric properties of the femur, $a$ is the intercept, $\beta$ is the slope ratio, $X$ is the dietary $n$ - 3 PUFA content (expressed in $\mathrm{g} / \mathrm{kg}$ diet) or $n-6$ : $n-3$ PUFA ratio or empty body $n-3$ PUFA content (expressed in $\mathrm{g} / \mathrm{kg}$ diet) or $n-6: n-3$ PUFA ratio.

\section{Results}

\section{Fat and fatty acid contents in the diets}

Diets $\mathrm{L}, \mathrm{F}$ and $\mathrm{T}$ had similar amount of fat and fatty acids but higher than those of diet C (Table 2). The $n$-3 PUFA content was approximately $6.5 \%(\operatorname{diet} \mathrm{C}), 13.5 \%(\operatorname{diet} \mathrm{T}), 50 \cdot 9 \%(\operatorname{diet} \mathrm{F})$ and $52.4 \%$ (diet L) of the PUFA content of each diet. The ALA content was found to be the highest in diet $\mathrm{L}$, much lower in diet $\mathrm{F}$, lower in diet $\mathrm{T}$ and the lowest in $\operatorname{diet} \mathrm{C}(18.52,6.23,1.73$ and $0.62 \mathrm{~g} / \mathrm{kg}$, respectively). The EPA, DPA and DHA content were determined only for diet $\mathrm{F}(8 \cdot 21 \mathrm{~g} / \mathrm{kg})$. The $n-6: n-3$ PUFA ratio took the following order 0.91 (in diet L), 0.96 (in diet F), 6.42 (in $\operatorname{diet} \mathrm{T}$ ) and 14.60 (in $\operatorname{diet} \mathrm{C}$ ).

\section{Performance of animals}

The average daily gain, daily feed intake (including both lysine and metabolisable energy), final protein, diethyl ether extract and ash contents measured in the empty body weight were not found to differ between the groups of pigs (Table 3 ).

\section{Fatty acid content in the empty body}

Dietary treatment affects the content of individual fatty acids in the empty body of pigs (Table 4). Content of SFA and MUFA did not differ among groups $\mathrm{C}, \mathrm{T}$ and $\mathrm{F}$; however, it was higher than in group $\mathrm{L}(P<0.05)$. The content of PUFA was the highest in group $\mathrm{L}$, lower in group $\mathrm{F}$ and the lowest in groups $\mathrm{C}$ and $\mathrm{T}$ $(P=0.010)$. Content of $n$-6 PUFA and LA took the following order: $\mathrm{L}>\mathrm{F}>\mathrm{C}>\mathrm{T}(P=0 \cdot 010)$. Empty body of $\mathrm{T}, \mathrm{C}$ and $\mathrm{F}$ pigs had similar amount of arachidonic acid (AA, C20 : 4n-6), however, lower than in L pigs $(P=0 \cdot 007)$. Content of $n-3$ PUFA and ALA took the following order: $\mathrm{L}>\mathrm{F}>\mathrm{T}$ and $\mathrm{C}(P=0 \cdot 010)$. Content of EPA, DPA and DHA was the highest in $\mathrm{F}$ pigs, lower in $\mathrm{L}$ pigs and the lowest in $\mathrm{C}$ and $\mathrm{T}$ pigs $(P<0 \cdot 010)$. The $n-6: n-3$ PUFA ratio in the empty body was similar in pigs of groups $\mathrm{C}$ and $\mathrm{T}$, however higher compared with groups $\mathrm{F}$ and $\mathrm{L}$ (average 5.57, 1.71 and $1.20 ; P=0.006)$.

\section{Femur parameters}

Dietary treatment was not found to have an effect on the mass and length of the femur (Table 5). The femurs of pigs in groups $\mathrm{C}$ and $\mathrm{T}$ had similar, though lower, cortical wall thickness $(P=0 \cdot 008)$, cross-sectional area $(P=0.004)$, cortical index $(P=0.016)$, bone mineral content $(P=0 \cdot 001)$, bone mineral density $(P=0.005)$, maximum elastic strength $(P=0.005)$ and maximum strength $(P=0.003)$ than those of pigs in groups $\mathrm{L}$ and $\mathrm{F}$.

The relationships determined between dietary n-3 PUFA content and n-6:n-3 PUFA ratio and femur geometric, densitometric and biomechanical properties are shown in Table 6. Concerning relationships between dietary $n$-3 PUFA content and femur properties (except cortical wall thickness), a significant and positive correlations were found ( $r$ ranged from 0.39 to $0 \cdot 64$ ). In contrary, relationship between dietary $n-6: n-3$ PUFA ratio and cross-sectional area, bone mineral content, bone mineral density, maximum elastic strength of femur was significant and negative ( $r$ ranged from -0.43 to -0.54 ).

The relationships determined between the empty body fatty acid composition and femur geometric, densitometric and biomechanical properties are shown in Table 7 . Relationships between $n$-3 PUFA content in the empty body and femur properties (except cortical wall thickness) were significant and positive ( $r$ ranged from 0.36 to 0.67 ). In contrary, relationships between $n-6: n-3$ PUFA ratio in the empty body and femur properties (except cortical wall thickness) were significant and negative ( $r$ ranged from -0.39 to $-0 \cdot 61$ ). 
Table 3. Performance of pigs during experimental period and final body composition (Mean values and standard deviations)

\begin{tabular}{|c|c|c|c|c|c|c|c|c|c|}
\hline \multirow[b]{3}{*}{ Item } & \multicolumn{8}{|c|}{ Group $(n 8)$} & \multirow[b]{3}{*}{$P$ (ANOVA) } \\
\hline & \multicolumn{2}{|c|}{ C } & \multicolumn{2}{|c|}{ L } & \multicolumn{2}{|c|}{$\mathrm{F}$} & \multicolumn{2}{|c|}{$\mathrm{T}$} & \\
\hline & Mean & SD & Mean & SD & Mean & SD & Mean & SD & \\
\hline Daily feed intake $(\mathrm{kg})$ & 2.5 & 0.01 & 2.5 & 0.01 & 2.5 & 0.01 & 2.5 & 0.01 & 0.959 \\
\hline Daily metabolisable energy intake (MJ) & 33.6 & 0.69 & 33.9 & 0.71 & $34 \cdot 0$ & 0.70 & $34 \cdot 0$ & 0.68 & 0.823 \\
\hline Daily Lys intake (g) & $20 \cdot 4$ & 0.50 & 20.5 & 0.51 & 20.6 & 0.52 & 20.5 & 0.52 & 0.948 \\
\hline Average daily gain $(\mathrm{g})$ & 945 & 45 & 985 & 53 & 973 & 49 & 969 & 48 & 0.886 \\
\hline Empty body weight $(\mathrm{kg})$ & $103 \cdot 8$ & 2.62 & $104 \cdot 0$ & 2.51 & 103.4 & $2 \cdot 19$ & $104 \cdot 2$ & 2.42 & 0.703 \\
\hline \multicolumn{10}{|c|}{ Final body composition ( $\mathrm{g} / \mathrm{kg}$ empty body weight) } \\
\hline Protein & 166 & 5.09 & 167 & $5 \cdot 14$ & 164 & 4.51 & 164 & 5.09 & 0.472 \\
\hline Diethyl ether extract & 178 & 12.41 & 183 & $15 \cdot 26$ & 184 & 11.29 & 192 & 7.79 & 0.454 \\
\hline Ash & $26 \cdot 60$ & 1.42 & $27 \cdot 87$ & 1.72 & 28.33 & 1.47 & $26 \cdot 71$ & 0.86 & 0.425 \\
\hline
\end{tabular}

C, pigs fed a control diet; L, pigs fed a diet rich in a-linolenic acid (from linseed oil); F, pigs fed a diet rich in EPA and DHA (from fish oil); T, pigs fed a diet rich in SFA (from beef tallow).

Table 4. Fatty acid content in the empty body of pigs at the end of the study (at $165 \mathrm{~d}$ of age) (Mean values and standard deviations)

\begin{tabular}{|c|c|c|c|c|c|c|c|c|c|}
\hline \multirow[b]{3}{*}{ Item } & \multicolumn{8}{|c|}{ Group ( $n$ 8) } & \multirow[b]{3}{*}{$P$ (ANOVA) } \\
\hline & \multicolumn{2}{|c|}{ C } & \multicolumn{2}{|c|}{$\mathrm{L}$} & \multicolumn{2}{|c|}{$\mathrm{F}$} & \multicolumn{2}{|c|}{$\mathrm{T}$} & \\
\hline & Mean & SD & Mean & SD & Mean & SD & Mean & SD & \\
\hline SFA (kg) & $6.45^{\mathrm{b}}$ & 0.21 & $5.86^{\mathrm{a}}$ & 0.19 & $6 \cdot 43^{\mathrm{b}}$ & 0.20 & $6.49^{\mathrm{b}}$ & 0.22 & 0.048 \\
\hline MUFA (kg) & $7.18^{\mathrm{b}}$ & 0.15 & $6.59^{\mathrm{a}}$ & 0.14 & $7 \cdot 22^{\mathrm{b}}$ & 0.15 & $7 \cdot 31^{\mathrm{b}}$ & 0.15 & 0.050 \\
\hline PUFA (kg) & $2 \cdot 18^{A}$ & 0.14 & $4 \cdot 19^{C}$ & 0.27 & $3.16^{\mathrm{B}}$ & 0.21 & $2 \cdot 10^{\mathrm{A}}$ & 0.14 & 0.010 \\
\hline$n-6$ PUFA (g) & $1854^{\mathrm{B}}$ & $48 \cdot 18$ & $2288^{\mathrm{D}}$ & 59.50 & $1996^{\mathrm{C}}$ & 51.91 & $1770^{\mathrm{A}}$ & 46.02 & 0.010 \\
\hline C18:2n-6 & $1754^{\mathrm{B}}$ & $45 \cdot 60$ & $2162^{\mathrm{D}}$ & 56.21 & $1910^{C}$ & 49.66 & $1670^{A}$ & 43.42 & 0.010 \\
\hline $\mathrm{C} 20: 4 n-6$ & $99.4^{\mathrm{A}}$ & 4.27 & $125 \cdot 9^{\mathrm{B}}$ & 5.41 & $85.6^{\mathrm{A}}$ & 3.68 & $99.9^{\mathrm{A}}$ & 4.30 & 0.007 \\
\hline n-3 PUFA (g) & $323^{A}$ & 11.29 & $1904^{C}$ & 49.32 & $1165^{\mathrm{B}}$ & 40.78 & $328^{A}$ & 11.31 & 0.000 \\
\hline C18:3n-3 & $288^{\mathrm{A}}$ & 13.25 & $1808^{C}$ & 83.01 & $618^{\mathrm{B}}$ & 28.82 & $293^{A}$ & 13.45 & 0.008 \\
\hline $\mathrm{C} 20: 3 n-6$ & ND & - & ND & - & ND & - & ND & - & - \\
\hline C20:5n-3 & $4.5^{\mathrm{A}}$ & 0.31 & $32.4^{\mathrm{B}}$ & $2 \cdot 27$ & $108 \cdot 7^{\mathrm{C}}$ & $7 \cdot 71$ & $4 \cdot 2^{\mathrm{A}}$ & 0.15 & 0.009 \\
\hline C22: $5 n-3$ & $21.9^{A}$ & 1.00 & $52.6^{\mathrm{B}}$ & 2.42 & $168.9^{\mathrm{C}}$ & 7.77 & $21 \cdot 8^{\mathrm{A}}$ & 0.95 & 0.008 \\
\hline C22: $6 n-3$ & $8 \cdot 1^{\mathrm{A}}$ & 0.53 & $10 \cdot 7^{\mathrm{B}}$ & 0.73 & $269 \cdot 2^{\mathrm{C}}$ & $18 \cdot 31$ & $8.5^{\mathrm{A}}$ & 0.71 & 0.009 \\
\hline$n-6: n-3$ PUFA & $5 \cdot 74^{\mathrm{C}}$ & 0.17 & $1.20^{\mathrm{A}}$ & 0.03 & $1.71^{\mathrm{B}}$ & 0.05 & $5 \cdot 40^{C}$ & 0.16 & 0.006 \\
\hline
\end{tabular}

C, pigs fed a control diet; L, pigs fed a diet rich in a-linolenic acid (from linseed oil); F, pigs fed a diet rich in EPA and DHA (from fish oil); T, pigs fed a diet rich in SFA (from beef tallow); ND, value below 0.01 was classified as not determined. A,B Mean values within a row with unlike superscript letters were significantly different $(P<0.01)$.

a,b Mean values within a row with unlike superscript letters were significantly different $(P<0.05)$ 


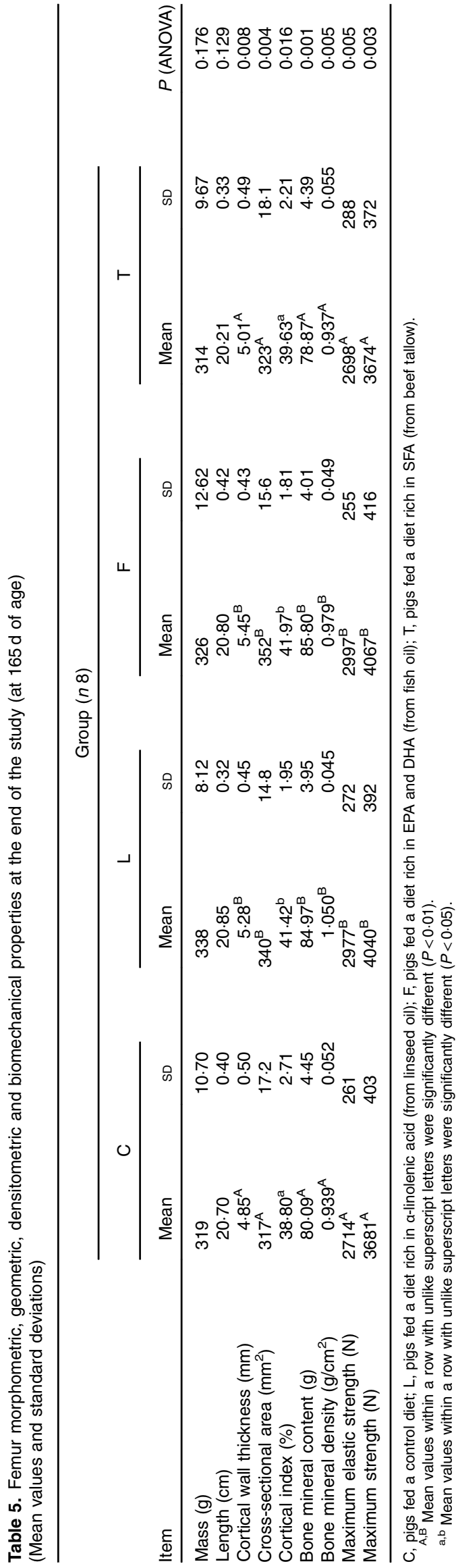

\section{Discussion}

\section{Limitations of the study}

The presented results come from an experiment on the impact of $n-3$ PUFA on the health-promoting properties of pork. Therefore, in this article we did not deal with the effect of $n-6$ PUFA on bone properties. The femur was collected additionally as the bone most commonly used in human osteoporosis research. We focused on densitometry parameters as these factors are commonly measured in human medicine. Moreover, they have great impact on bone strength. This study, however, did not provide a complete picture of the influence of dietary $n-3$ PUFA on bone parameters, as we consider this effect only on the entire femur without taking into account bone microarchitecture. Undoubtedly, combination of adequate mineralisation and microarchitecture forms a strong and flexible bone highly resistant to fracture. However, differentiation of femur tissue into trabecular and cortical would allow to make our findings more precise. It is well known that trabecular bone is more metabolically active and undergoing more rapid remodelling than cortical bone, thus, the influence of dietary factors firstly occurs in trabecular tissue. Moreover, addition of fatty acids' analyses from the animals' serum undoubtedly improves the value of the manuscript, but unfortunately we have no such data. However, we have data concerning fatty acid content in the empty body. In our opinion, it is equivalent (or more precise) information as fatty acid content in the serum, because it reflects the total amount of fatty acids deposited by animal.

Furthermore, it was assumed that in the study on the influence of various types of fat sources on the investigated parameters, the pigs of control group should be fed diet not supplemented with any source of fat. As the study was carried out in the last period of pig fattening, feed ingredients of the $\operatorname{diet} \mathrm{C}$ include the amount of energy that fully covered the requirements of pigs of this weight category. Therefore, additional source of energy (in fat form) was not required. Because SFA usually has a negative impact on bone properties ${ }^{(28,29)}$, group of pigs fed diet $\mathrm{T}$ may be considered as a negative control group.

\section{Animal performance and fatty acid contents in the empty body}

As the energetic and nutritive values of pig diets as well as their feed intakes were equalised between the different groups of pigs, only their fatty acid intake differed, and this was dependent on the source of fat that was added to their diets. Therefore, the growth rate and fat and protein contents in the body did not differ between treatments. Previous studies carried out on pigs ${ }^{(30,31)}$ and quails $^{(6)}$ showed similar response. In contrast, rats fed diets rich in $n$-6 PUFA (mainly linoleic acid (LA, C18:2n-6) from sunflower and soyabean oils) and broilers fed diets rich in $n$-3 PUFA (mainly ALA from linseed oil) had lower body fat accumulation compared with their counterparts that were fed diets rich in SFA (from beef tallow), as reported by Matsuo et al. ${ }^{(32)}$ and Crespo \& EsteveGarcia $^{(33)}$, Smink et al. ${ }^{(34)}$, respectively. Crespo \& Esteve-Garcia ${ }^{(33)}$ suggest that a possible reason for the reduction in abdominal fat in broilers fed diets rich in ALA (from linseed oil) may be a result of higher lipid oxidation, as fats rich in $n-3$ PUFA are known to be 
Table 6. Relationship $(Y=a+\beta X)$ between femur properties and dietary $n-3$ PUFA content $(\mathrm{g} / \mathrm{kg})$ and $n-6: n-3$ PUFA ratio $(n 32)$ (Mean values and standard deviations)

\begin{tabular}{|c|c|c|c|c|c|c|c|}
\hline \multirow[b]{2}{*}{ Properties of femur $(Y)$} & \multicolumn{2}{|c|}{ a } & \multicolumn{2}{|c|}{$\beta$} & \multirow[b]{2}{*}{ Fatty acids content in the diet $(X)$} & \multirow[b]{2}{*}{$r$} & \multirow[b]{2}{*}{$P$} \\
\hline & Mean & SD & Mean & SD & & & \\
\hline Cortical wall thickness (mm) & 0.519 & 0.010 & 0.0004 & 0.000 & $n-3$ PUFA & 0.08 & 0.666 \\
\hline Cross-sectional area $\left(\mathrm{mm}^{2}\right)$ & 332 & 7.073 & 1.479 & 0.028 & $n-3$ PUFA & 0.44 & 0.020 \\
\hline Cortical index (\%) & 39.622 & 0.579 & 0.095 & 0.034 & $n-3$ PUFA & 0.39 & 0.050 \\
\hline Bone mineral content $(\mathrm{g})$ & $80 \cdot 319$ & $1 \cdot 128$ & 0.279 & 0.052 & $n-3$ PUFA & 0.50 & 0.007 \\
\hline Bone mineral density $\left(\mathrm{g} / \mathrm{cm}^{2}\right)$ & 0.941 & 0.013 & 0.004 & 0.000 & $n-3$ PUFA & 0.64 & 0.001 \\
\hline Maximum strength $(\mathrm{N})$ & $2564 \cdot 21$ & $85 \cdot 30$ & 11.564 & 3.856 & $n-3$ PUFA & 0.43 & 0.023 \\
\hline Maximum elastic strength $(\mathrm{N})$ & 3543 & $108 \cdot 0$ & 30.661 & 6.737 & $n-3$ PUFA & 0.55 & 0.003 \\
\hline Cortical wall thickness $(\mathrm{mm})$ & 0.524 & 0.012 & -0.0008 & 0.001 & $n-6: n-3$ PUFA & -0.01 & 0.951 \\
\hline Cross-sectional area $\left(\mathrm{mm}^{2}\right)$ & 358 & 7.028 & -0.216 & 0.7281 & $n-6: n-3$ PUFA & -0.43 & 0.020 \\
\hline Cortical index (\%) & 41.139 & 0.458 & -0.110 & 0.0392 & $n-6: n-3$ PUFA & -0.28 & 0.056 \\
\hline Bone mineral content $(\mathrm{g})$ & 84.177 & 1.089 & -0.228 & 0.075 & $n-6: n-3$ PUFA & -0.47 & 0.015 \\
\hline Bone mineral density $\left(\mathrm{g} / \mathrm{cm}^{2}\right)$ & 1.011 & 0.014 & -0.005 & 0.002 & $n-6: n-3$ PUFA & -0.50 & 0.007 \\
\hline Maximum strength $(\mathrm{N})$ & 2922.65 & $75 \cdot 625$ & $-18 \cdot 133$ & $2 \cdot 941$ & $n-6: n-3$ PUFA & -0.38 & 0.089 \\
\hline Maximum elastic strength $(\mathrm{N})$ & $3627 \cdot 25$ & $105 \cdot 171$ & -44.307 & 1.327 & $n-6: n-3$ PUFA & -0.54 & 0.003 \\
\hline
\end{tabular}

Table 7. Relationship $(Y=a+\beta X)$ between femur properties and empty body $n-3$ PUFA content $(\mathrm{g} / \mathrm{kg})$ and $n-6: n-3$ PUFA ratio ( $n$ 32) (Mean values and standard deviations)

\begin{tabular}{|c|c|c|c|c|c|c|c|}
\hline \multirow[b]{2}{*}{ Properties of femur $(Y)$} & \multicolumn{2}{|c|}{ a } & \multicolumn{2}{|c|}{$\beta$} & \multirow[b]{2}{*}{ Fatty acids content in the empty body $(X)$} & \multirow[b]{2}{*}{$r$} & \multirow[b]{2}{*}{$P$} \\
\hline & Mean & SD & Mean & SD & & & \\
\hline Cortical wall thickness $(\mathrm{mm})$ & 0.521 & 0.013 & 0.00003 & 0.000 & $n-3$ PUFA & 0.05 & 0.723 \\
\hline Cross-sectional area $\left(\mathrm{mm}^{2}\right)$ & 336 & 7.832 & 0.009 & 0.007 & $n-3$ PUFA & 0.41 & 0.049 \\
\hline Cortical index (\%) & 39.488 & 0.576 & 0.001 & 0.000 & $n-3$ PUFA & 0.36 & 0.043 \\
\hline Bone mineral content $(\mathrm{g})$ & $79 \cdot 772$ & $1 \cdot 121$ & 0.003 & 0.000 & $n-3$ PUFA & 0.52 & 0.002 \\
\hline Bone mineral density $\left(\mathrm{g} / \mathrm{cm}^{2}\right)$ & 0.929 & 0.013 & 0.0006 & 0.000 & $n-3$ PUFA & 0.67 & 0.000 \\
\hline Maximum strength $(\mathrm{N})$ & $2652 \cdot 01$ & 79.80 & 0.175 & 0.070 & $n-3$ PUFA & 0.41 & 0.019 \\
\hline Maximum elastic strength $(\mathrm{N})$ & 3509.75 & 111 & 0.331 & 0.098 & $n-3$ PUFA & 0.53 & 0.002 \\
\hline Cortical wall thickness $(\mathrm{mm})$ & 0.532 & 0.015 & -0.0023 & 0.001 & $n-6: n-3$ PUFA & $-0 \cdot 12$ & 0.527 \\
\hline Cross-sectional area $\left(\mathrm{mm}^{2}\right)$ & 367.63 & 7.967 & $-6 \cdot 231$ & 1.912 & $n-6: n-3$ PUFA & -0.51 & 0.003 \\
\hline Cortical index (\%) & 41.788 & 0.620 & -0.366 & 0.156 & $n-6: n-3$ PUFA & -0.39 & 0.026 \\
\hline Bone mineral content $(\mathrm{g})$ & $86 \cdot 309$ & 1.305 & -0.978 & 0.313 & $n-6: n-3$ PUFA & -0.50 & 0.004 \\
\hline Bone mineral density $\left(\mathrm{g} / \mathrm{cm}^{2}\right)$ & 1.036 & 0.016 & -0.016 & 0.004 & $n-6: n-3$ PUFA & -0.61 & 0.000 \\
\hline Maximum strength $(\mathrm{N})$ & 3026.02 & 89.685 & $-59 \cdot 36$ & 21.523 & $n-6: n-3$ PUFA & -0.45 & 0.009 \\
\hline Maximum elastic strength $(\mathrm{N})$ & 4206.05 & 124.75 & -108.85 & 29.938 & $n-6: n-3$ PUFA & -0.55 & 0.001 \\
\hline
\end{tabular}

more sensitive to oxidation. This effect has also been observed by other researchers ${ }^{(35,36)}$

The results of the present study clearly showed that dietary fatty acids strongly influenced fatty acid content in the empty body, as pigs consumed diet rich in ALA (from linseed oil) and EPA and DHA (from fish oil) increased the amount of these fatty acids in their empty body compared with those animals fed diet rich in SFA (from beef tallow) and control diet. Other authors also demonstrate that dietary PUFA (both $n$ - 6 and $n$-3) modify fatty acid composition in rats' bone tissue ${ }^{(12)}$ and in the liver and serum of piglets ${ }^{(16)}$. Our earlier study ${ }^{(36)}$ showed that if pigs consumed a diet rich in ALA up to $82 \%$ of consumed ALA can be directly deposited in the body. Moreover, such fed pigs assigned quantitatively higher amount of ALA to further bioconversion to longer-chain $n$-3 PUFA compared with animals fed the diets poorer in those fatty acids.

\section{Effect of dietary source of fat on femur properties}

The results of the present study indicate that the dietary source of fat, as a carrier of fatty acids, may affect bone health. Our study results confirm the findings of other studies ${ }^{(6,7,16,37-39)}$, indicating that a diet rich in $n$-3 PUFA may positively influence bone health. However, it is difficult to perform a direct comparison between presented and cited results due to species difference (rodents, poultry and piglets), examined bones and different amounts and sources of dietary fat used in the cited studies. Furthermore, the results of the studies carried out on rodents and poultry cannot be applied to human studies. However, our intention was to use pigs as an animal model for humans. Recent studies have demonstrated that, for humans, pigs are a better model than rodents and poultry owing to several similarities in anatomy, physiology, metabolism and pathology ${ }^{(40-42)}$. Obviously, there are inter-species differences in the skeletal structure and load, however, our research interests focus on the effects of factors that affect the properties of pig and human bones in a similar manner. Therefore, in the present study, we decided to investigate the influence of the fatty acid content of diet and empty body on a range of femoral parameters (morphometric, geometric, densitometric and biomechanical) in growing pigs. These analyses will aid our understanding of the relationship between both dietary and 
empty body fatty acid composition and bone properties as well as the metabolic processes involved in this response.

The main finding of the present study carried out on a growing pig model is that consumption of a diet rich in ALA (from linseed oil) improved femur geometrical, biomechanical and densitometric properties to a similar extent as that observed following consumption of a diet rich in EPA and DHA (from fish oil).

Concerning the geometrical and biomechanical properties of the femur in the present study, we observed that consumption of diets rich in ALA (from linseed oil) and EPA and DHA (from fish oil) by pigs significantly improved these tested parameters compared with those of pigs fed a diet rich in SFA (from beef tallow) or a control diet. A review of the current literature did not reveal any information on the simultaneous comparison of the effect of diets rich in ALA $v$. EPA and DHA $v$. SFA on bone properties. Previous studies ${ }^{(6,8-10,20)}$ indicate that longer-chain $n$-3 PUFA, particularly DHA, can have potentially favourable effects on bone health. Liu et al. ${ }^{(6)}$ showed that quails fed a diet rich in EPA and DHA (from fish oil) had higher cortical bone thickness and improved bone mineralisation and mechanical strength of tibia than those fed diets containing $n-6$ PUFA (from soyabean oil) and SFA (from poultry fat). Analogously, Reinwald et al. ${ }^{(43)}$ found that rats fed diets deficient in $n$-3 PUFA had a significantly lower mechanical strength of the tibia compared with those fed diets with an adequate amount of $n-3$ PUFA. However, in this study the experimental factor did not affect the femur properties. It seems that the variation in response of animal on experimental treatment may depend on the type of bone being examined. The cited authors suggested that the tibia may be more sensitive than the femur to the action of dietary $n-3$ PUFA for bone modelling. Furthermore, Reinwald et $a l .{ }^{(43)}$ showed that dietary $n-3$ PUFA supplementation restored the tibia $n-6: n-3$ PUFA ratio and reversed compromised bone modelling in rats that had been fed a diet deficient in $n$-3 PUFA. In a study carried out on chickens, Baird et al. ${ }^{(20)}$ demonstrated that the cortical thickness of the tibia improved with the addition of increasing amounts of $n$ - 3 PUFA into the diet. However, in contrast to our results, bone strength was not found to be improved. Liu et al. ${ }^{(6)}$ suggest that the effect of dietary lipids on bone mineralisation is a cumulative process and that long-term dietary supplementation amplifies the effects of lipid turnover. The beneficial effects of $n-3$ PUFA on human bone health were also observed by Rousseau et al. ${ }^{(44)}$. The cited authors observed a positive relation between the daily intake of $n$-3 PUFA and the femoral neck bone mineral density of elderly men and women (of 60 years of age or older). In contrast, the results of a study by Mollard et al. ${ }^{(17)}$ carried out on piglets demonstrated that AA and DHA supplementation improved bone mineral content and density in lumbar spine but did not affect femur mineralisation. However, other researchers $^{(20)}$ were unable to demonstrate a positive effect of $n$-3 PUFA on animal bone parameters. A possible reason for the discrepancies between our findings and those of the cited authors may result from differences in bone growth, the type of bone used, difference between species and differences in the sex and age of the animals used in the studies. In general, the maximum rate of bone formation occurs during the earliest stage of animal growth (e.g. in pigs, this is during the first 12 weeks of life ${ }^{(45)}$ ). Thus, action of dietary treatment could take place at various times of bone/skeleton development. Difficulties in comparing the results of the studies indicated that further research is needed to determine the extent to which $n$-3 PUFA influences the metabolic activity of individual bones (long, flat and sesamoid) and mineral accretion at specific skeletal sites using animal model.

Concerning bone features measured using dual-energy X-ray absorptiometry method, we found that consumption of a diet rich in ALA (from linseed oil) improved femur mineral content and mineral density to a similar extent as that observed following the consumption of a diet rich in EPA and DHA (from fish oil). Fallon et $a l .{ }^{(14)}$ found a positive effect of diet rich in DHA on femur cortical mineral density and trabecular microstructure but not on trabecular mineral density. The results of the study carried out on growing rats by $\mathrm{Li}$ et $a l^{(12)}$ indicated that DHA accumulates in the osteoblast-rich and nerveabundant periosteum of femur and appears to be a vital constituent of healthy modelling bone. Moreover, both cited authors found that consumption of a diet rich in DHA has a protective effect against trabecular bone loss, which is achieved among other by increase in the number of trabecular elements and subsequent strengthening of the trabecular network. The mechanisms by which dietary fat influences bone metabolism and function are not completely understood. Several mechanisms can be involved in the positive effect of diet rich in $n$-3 PUFA on bone health. Both LA and ALA are precursors of longer-chain $n-6$ and $n$-3 PUFA, respectively. These fatty acids compete for the enzyme $\Delta^{6}$-desaturase, which is necessary for de novo synthesis of longer-chain fatty acids ${ }^{(35,46)}$. Therefore, diets containing different amounts of these fatty acids introduce different amounts of substrates for $n-6$ and $n-3$ pathways. Previous studies $^{(6)}$ suggest that the action of ALA is achieved indirectly through its bioconversion, within the organism, into longer-chain $n-3$ PUFA. However, the efficiency of the bioconversion of ALA to longer-chain $n-3$ PUFA is dependent upon the expected end products ${ }^{(35,36,47,48)}$. In humans ${ }^{(47)}$, bioconversion of ALA to EPA (from 0.2 to $6 \%$ ) and DPA (from $0 \cdot 13$ to $6 \%$ ) is generally limited, and the synthesis of DHA is highly constrained (up to maximum 0.05\%). However, in pigs, bioconversion of ALA to longer-chain $n$ - 3 PUFA ranged from 3.7 to $6 \cdot 3 \%^{(36)}$, some authors reported that even up to $13 \%{ }^{(48)}$. It seems that the second factor that affects the efficiency of this bioconversion appears to be the content of ALA in the diet ${ }^{(36)}$. A study by Poureslami et al. ${ }^{(35)}$ demonstrated that dietary provision (abundance) of ALA promotes apparent elongation and desaturation activity on the $n-3$ PUFA pathway. In contrast, if the diet is supplemented with EPA and DHA (from fish oil), bioconversion (elongation and desaturation) of ALA is suppressed and a great amount of ALA is oxidised. In turn, the end products of these bioconversions act as substrates for other biologically active substances such as eicosanoids ${ }^{(15,37)}$. For example, the 3-series $\mathrm{PG}\left(\mathrm{PGE}_{3}\right)$ synthetised during bioconversion pathways of EPA and DHA have an anti-inflammatory effect which supports bone formation process ${ }^{(12)}$. In turn, 2-series $\mathrm{PG}\left(\mathrm{PGE}_{2}\right)$ synthesised during bioconversion of AA have a pro-inflammatory effect leading to the increase in the intensity of bone resorption process. 
Moreover, $\mathrm{PGE}_{2}$ is known to enhance receptor activator of NF$\kappa B$ (RANK) expression in pre-osteoclasts, possibly leading to enhanced osteoclastogenesis and consequently bone resorption $^{(49)}$. Some researchers suggest that bioactive substances deliver from AA metabolism pathway (e.g. pro-inflammatory cytokines: IL-1, IL-6, TNF- $\alpha$ ) involved in immune response that negatively affect bone growth and properties ${ }^{(50)}$. On the other hand, various $n-3$ PUFA can reverse this trend in bone cells due to reduced osteoclastogenesis resulting from higher amount of resolvins in bone marrow and the associated reduction in gene expression connected with bone resorption process (e.g. TNF- $\alpha$, RANK) ${ }^{(51)}$. Thus, it seems that EPA acts as a competitive inhibitor for production of bioactive substances derived from AA. It is well known that bioconversion of these fatty acids is supported by the same enzymes (e.g. cyclo-oxygenase and 5 -lipoxygenase $)^{(21)}$. Moreover, some authors ${ }^{(52,53)}$ found that when feed was supplemented with $n$-3 PUFA, an increased intestinal $\mathrm{Ca}$ absorption and bone $\mathrm{Ca}$ deposition were observed. It could be attributed to dietary-induced increase in circulating PG which in turn has a positive effect on bone. An increased synthesis of PG acts on target bone cells as well as changes the membrane structure and fluidity. This change facilitates permeation of vitamin $\mathrm{D}$, playing a crucial role in active transport of $\mathrm{Ca}$ across the cells membrane. Therefore, it can be concluded that if the content of EPA and DHA in the diet exceeds the content of AA, then less substrate is available for the synthesis of eicosanoids from AA. Thus, finally such fatty acid composition in the diet positively affects bone health

The important role of $n-3$ PUFA on bone health also proves significant positive correlations between the femur geometric, densitometric and biomechanical parameters and dietary $n-3$ PUFA content determined in the present study. In addition, about the essential role of $n-3$ PUFA on bone health indicates significant negative correlations found between the same parameters and dietary $n-6: n-3$ PUFA ratio. Moreover, as the dietary fatty acid content in the feed offered to animals strongly affects their empty body content, it should not come as a surprise that a relationship for empty body $n-3$ PUFA content or n-6:n-3 PUFA ratio and investigated femur parameters happened to be similar, or even stronger, as in the case of dietary fatty acid composition. Similar correlations have been found previously by several authors in studies with rats ${ }^{(12,38)}$ and in elderly humans ${ }^{(39,44)}$. However, Li et al. ${ }^{(12)}$ correlated $n$-3 PUFA content and $n-6: n-3$ PUFA ratio in the marrow and periosteum of femur and tibia with properties of these bones. Studies in humans have been carried out by Weiss et $a l^{(39)}$ and Rousseau et $a l^{\left({ }^{(44)}\right.}$. These studies were based on self-administered FFQ alone. In the cited studies, dietary (or bone) $n$ - 3 PUFA content and $n-6: n-3$ PUFA ratio were found to correlate with bone mineralisation parameters (mineral content and density) as measured by X-ray absorptiometry. However, as the relationships of both dietary and empty body $n-3$ PUFA content and $n$-6: $n-3$ PUFA ratio with other bone parameters such as geometry and biomechanical parameters were not investigated previously, it is difficult to conduct closer discussion. Thus, evaluation of the relationships among dietary and empty body fatty acid composition and femur geometric, densitometric and biomechanical parameters are crucial for further understanding of the role of these factors in the formation of bone properties as well as the in the metabolic pathways involved in these processes.

In conclusion, along with increasing consumption of $n-3$ PUFA, femur parameters happened to be significantly improved. Contrary, if dietary $n-6: n-3$ PUFA ratio increases, the measure of bone parameters deteriorate strongly. Relationships for $n-3$ PUFA content and $n-6: n-3$ PUFA ratio in the empty body and investigated properties of the femur are similar, or even stronger, compared with the case of dietary fatty acid composition. Furthermore, linseed oil appeared to have a positive effect on bone parameters similar to fish oil.

\section{Acknowledgements}

This research received no specific grant from any funding agency, commercial or not-for-profit sectors.

M. S., G. S. and S. R. conceived and designed the study, interpreted the data and drafted the manuscript. M. S. conducted the research and acquired the data and performed the statistical analysis.

The authors declare that there are no conflicts of interest.

\section{References}

1. Gutzwiller A, Hess HD, Adam A, et al. (2011) Effect of a reduced calcium, phosphorus and protein intake and of benzoic acid on calcium and phosphorus metabolism of growing pigs. Anim Feed Sci Technol 168, 113-121.

2. Varley PF, Callan JJ \& O'Doherty JV (2011) Effect of dietary phosphorus and calcium level and phytase addition on performance, bone parameters, apparent nutrient digestibility, mineral and nitrogen utilization of weaner pigs and the subsequent effect of finisher pig bone parameters. Anim Feed Sci Technol 165, 201-209.

3. Weremko D, Skiba G, Raj S, et al. (2013) The effects of feed and protein restriction between 90 and 118 days of age on performance, bone growth and mineralisation of pigs reared to 168 days of age. Anim Feed Sci Technol 182, 53-60.

4. Skiba G, Sobol M \& Raj S (2017) Femur morphometry, densitometry, geometry and mechanical properties in young pigs fed a diet free of inorganic phosphorus and supplemented with phytase. Arch Anim Nutr 71, 81-92.

5. Zernicke RF, Salem GJ, Barnard RJ, et al. (1995) Long-term, high-fat-sucrose diet alters rat femoral neck and vertebral morphology, bone mineral content, and mechanical properties. Bone 16, 25-31.

6. Liu D, Veit HP, Wilson JH, et al. (2003) Long-term supplementation of various dietary lipids alters bone mineral content, mechanical properties and histological characteristics of Japanese quail. Poult Sci 82, 831-839.

7. Lau BY, Cohen DJA, Ward WE, et al. (2013) Investigating the role of polyunsaturated fatty acid in bone development using animal models. Molecules 18, 14203-14227.

8. Parks CA (2016) The relationships between long-chain polyunsaturated fatty acid status and bone health in young children. $P h D$ Thesis. McGill University of Montreal.

9. Sun D, Krishnan A, Zaman K, et al. (2003) Dietary n-3 fatty acids decrease osteoclastogenesis and loss of bone mass in ovariectomized mice. J Bone Miner Res 18, 1206-1216.

10. Bhattacharya A, Rahman M, Sun D, et al. (2007) Effect of fish oil on bone mineral density in aging $\mathrm{C} 57 \mathrm{BL} / 6$ female mice. J Nutr Biochem 18, 372-379. 
11. Lau BY, Fajardo VA, McMeekin L, et al. (2010) Influence of high-fat diet from differential dietary sources on bone mineral density, bone strength, and bone fatty acid composition in rats. Appl Physiol Nutr Metab 35, 598-606.

12. Li Y, Seifert MF, Lim SY, et al. (2010) Bone mineral content is positively correlated to $n-3$ fatty acids in the femur of growing rats. BrJ Nutr 104, 674-685.

13. Bonnet N \& Ferrari SL (2011) Effects of long-term supplementation with omega-3 fatty acids on longitudinal changes in bone mass and microstructure in mice. J Nutr Biochem 22, 665-672.

14. Fallon EM, Nazarian A, Nehra D, et al. (2014) The effect of docosahexaenoic acid on bone microstructure in young mice and bone fracture in neonates. J Surg Res 191, 148-155.

15. Liu D, Veit HP \& Denbow DM (2004) Effects of long-term dietary lipids on mature bone mineral content, collagen, crosslinks, and prostaglandin E2 production in Japanese quail. Poult Sci 83, 1876-1883.

16. Weiler HA \& Fitzpatrick-Wong SC (2002) Modulation of essential (n-6):(n-3) fatty acid ratios alters fatty acid status but not bone mass in piglets. $J$ Nutr 132, 2667-2672.

17. Mollard RC, Kovacs HR, Fitzpatrick-Wong SC, et al. (2005) Low levels of dietary arachidonic and docosahexaenoic acids improve bone mass in neonatal piglets, but higher levels provide no benefit. $J$ Nutr 135, 505-512.

18. Judex S, Wohl G, Wolff R, et al. (2000) Dietary fish oil supplementation adversely affects cortical bone morphology and biomechanics in growing rabbits. Calcif Tissue Int $\mathbf{6 6}$, 443-448.

19. Weiler HA, Kovacs H, Nitschmann E, et al. (2007) Feeding flaxseed oil but not secoisolariciresinol diglucoside results in higher bone mass in healthy rats and rats with kidney disease. Prostaglandins Leukot Essent Fatty Acids 76, 269-275.

20. Baird HT, Eggett DL \& Fullmer S (2008) Varying ratios of omega-6:omega- 3 fatty acids on the pre and postmortem bone mineral density, bone ash, and bone breaking strength of laying chickens. Poult Sci 87, 323-328.

21. Ratnayake WM \& Galli C (2009) Fat and fatty acid terminology, methods of analysis and fat digestion and metabolism: a background review paper. Ann Nutr Metab 55, 8-43.

22. Kalish BT, Fallon EM \& Puder M (2012) A tutorial on fatty acid biology. J Parenter Enteral Nutr 36, 380-388.

23. National Research Council (2012) Nutrient Requirements of Swine, 11th rev. ed. Washington, DC: The National Academies Press.

24. Regulation (EC) No 1924/2006 of the European Parliament and of the Council with regard to the list of nutrition claims.

25. Ferretti JL, Capozza RF, Mondelo N, et al. (1993) Interrelationships between densitometric, geometric and mechanical properties of rat femora: inferences concerning mechanical regulation of bone modelling. J Bone Miner Res $\mathbf{8}$, 1389-1396.

26. Horwitz W \& Latimer GW (editors) (2011) Official Methods of Analysis of AOAC International, current through revision 4, 18th ed. Gaithersburg, MD: AOAC International.

27. Kratz R (2003) Effect of source of fat in the diet on the fatty acid profile and quality of the meat of pigs genetically differed in protein and lipid deposition. PhD Dissertation, Gießen, Germany (in German).

28. Lorincz C, Reimer RA, Boyd SK, et al. (2010) High-fat, sucrose diet impairs geometrical and mechanical properties of cortical bone in mice. Br J Nutr 103, 1302-1308.

29. Macri EV, Gonzales Chaves MM, Rodriguez PN, et al. (2012) High-fat diets affect energy and bone metabolism in growing rats. Eur J Nutr 51, 399-406.
30. Kouba M, Enser M, Whittington FM, et al. (2003) Effect of a high-linolenic acid diet on lipogenic enzyme activities, fatty acid composition, and meat quality in the growing pig. J Anim Sci 81, 1967-1979.

31. Olivares A, Daza A, Rey AI, et al. (2010) Effect of diet saturation on growth performance, carcass characteristics and fat quality of heavy pigs. Food Sci Technol Int 16, 321-327.

32. Matsuo T, Takeuchi H, Suzuki $\mathrm{H}$, et al. (2002) Body fat accumulation is greater in rats fed a beef tallow diet than in rats fed a safflower or soybean oil diet. Asia Pac J Clin Nutr 11, 302-308.

33. Crespo N \& Esteve-Garcia E (2002) Dietary linseed oil produces lower abdominal fat deposition but higher de novo fatty acid synthesis in broiler chickens. Poult Sci 81, 1555-1562.

34. Smink W, Gerrits WJJ, Hovenier R, et al. (2010) Effect of dietary fat sources on fatty acid deposition and lipid metabolism in broiler chickens. Poult Sci 89, 2432-2440.

35. Poureslami R, Turchini GM, Raes K, et al. (2010) Effect of diet, sex and age on fatty acid metabolism in broiler chickens: $n-3$ and n-6 PUFA. Br J Nutr 104, 204-213.

36. Skiba G, Poławska E, Sobol M, et al. (2015) Omega-6 and omega3 fatty acids metabolism pathways in the body of pigs fed diets with different sources of fatty acids. Arch Anim Nutr 69, 1-16.

37. Watkins B, Shen C, Allen K, et al. (1996) Dietary (n-3) and polyunsaturates and acetylsalicylic acid alter ex vivo PGE2 biosynthesis, tissue IGF-1 levels, and bone morphometry in chicks. J Bone Miner Res 11, 1321-1332.

38. Watkins BA, Li Y, Allen KG, et al. (2000) Dietary ratio of (n-6)/ $(n-3)$ polyunsaturated fatty acids alters the fatty acid composition of bone compartments and biomarkers of bone formation in rats. $J$ Nutr 130, 2274-2284.

39. Weiss LA, Barrett-Connor E \& von Mühlen D (2005) Ratio of $n-6$ to $n-3$ fatty acids and bone mineral density in older adults: the Rancho Bernardo Study. Am J Clin Nutr 81, 934-938.

40. Pearce AI, Richards RG, Milz S, et al. (2007) Animal models for implant biomaterial research in bone: a review. Eur Cell Mater 13, $1-10$

41. Reinwald S \& Burr D (2008) Review of nonprimate, large animal models for osteoporosis research.J Bone Miner Res $\mathbf{2 3}$, $1353-1368$

42. Aigner B, Renner S, Kessler B, et al. (2010) Transgenic pigs as models for translational biomedical research. $J$ Mol Med $\mathbf{8 8}$, 653-664.

43. Reinwald S, Li Y, Moriguchi T, et al. (2004) Repletion with $(n-3)$ fatty acids reverses bone structural deficits in (n-3)deficient rats. J Nutr 134, 388-394.

44. Rousseau JH, Kleppinger A \& Kenny AM (2009) Self-reported dietary intake of omega- 3 fatty acids and association with bone and lower extremity function. J Am Geriatr Soc 57, 1781-1788.

45. Heaney RP, Abrams S, Dawson-Hughes B, et al. (2000) Peak bone mass. Osteoporos Int 11, 985-1009.

46. Turchini GM \& Francis DS (2009) Fatty acid metabolism (desaturation, elongation and b-oxidation) in rainbow trout fed fish oil- or linseed oil-based diets. Br J Nutr 102, 69-81.

47. Burdge GC \& Calder PC (2005) Conversion of alpha linolenic acid to longer-chain polyunsaturated fatty acids in human adults. Reprod Nutr Dev 45, 581-597.

48. Kloareg M, Noblet J \& Van Milgen J (2007) Deposition of dietary fatty acids, de novo synthesis and anatomical partitioning of fatty acids in finishing pigs. Br J Nutr 97, 35-44.

49. Liu XH, Kirschenbaum A, Yao S, et al. (2006) Interactive effect of interleukin- 6 and prostaglandin E2 on osteoclastogenesis via the OPG/RANKL/RANK system. Ann N Y Acad Sci 1068, $225-233$ 
50. Das UN (2000) Essential fatty acids and osteoporosis. Nutrition 16, 386-390.

51. Poulsen RC, Gotlinger K, Serhan CN, et al. (2008) Identification of inflammatory and proresolving lipid mediators in bone marrow and theirlipidomic profiles with ovariectomy and omega 3 intake. Am J Hematol 83, 437-445.
52. Classen N, Coetzer H, Steinmann CM, et al. (1995) The effect of different $n-6 / n-3$ essential fatty acid ratios on calcium balance and bone in rats. Prostaglandins Leukot Essent Fatty Acids 53, 13-19.

53. Heaney RP, Carey R \& Harkness L (2005) Roles of vitamin D, $n-3$ polyunsaturated fatty acid, and soy isoflavones in bone health. J Am Diet Assoc 105, 1700-1702. 